Document downloaded from:

http://hdl.handle.net/10251/57921

This paper must be cited as:

Padin Devesa, J.; Martín Furones, AE.; Anquela Julián, AB. (2012). ARCHAEOLOGICAL MICROGRAVIMETRIC PROSPECTION INSIDE DON CHURCH (VALENCIA, SPAIN). Journal of Archaeological Science. 39(2):547-554. doi:10.1016/j.jas.2011.10.012.

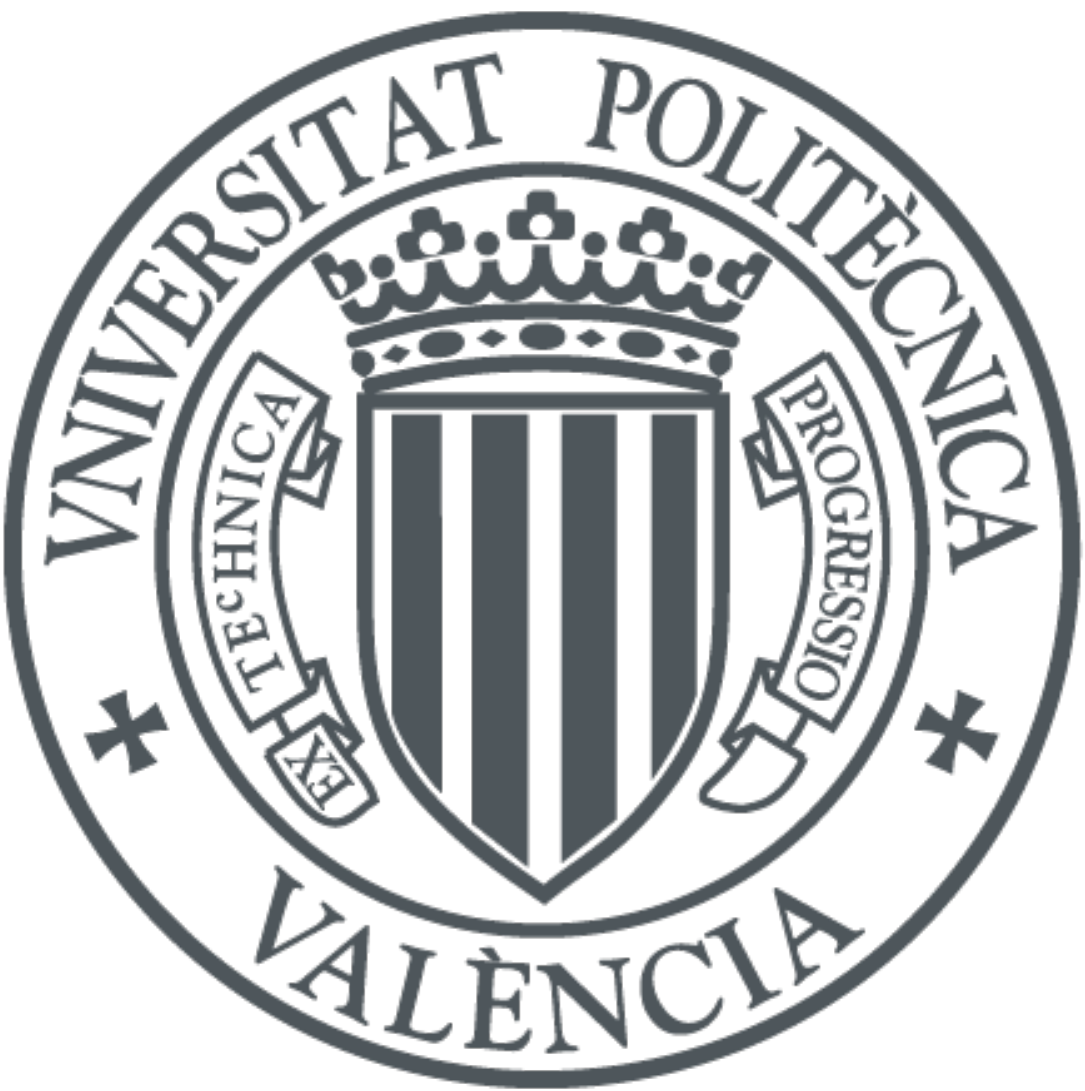

The final publication is available at

http://dx.doi.org/10.1016/j.jas.2011.10.012

Copyright Elsevier

Additional Information 
Document downloaded from:

http://hdl.handle.net/10251/57921

This paper must be cited as:

Padin Devesa, J.; Martín Furones, AE.; Anquela Julián, AB. (2012). ARCHAEOLOGICAL MICROGRAVIMETRIC PROSPECTION INSIDE DON CHURCH (VALENCIA, SPAIN). Journal of Archaeological Science. 39(2):547-554. doi:10.1016/j.jas.2011.10.012.

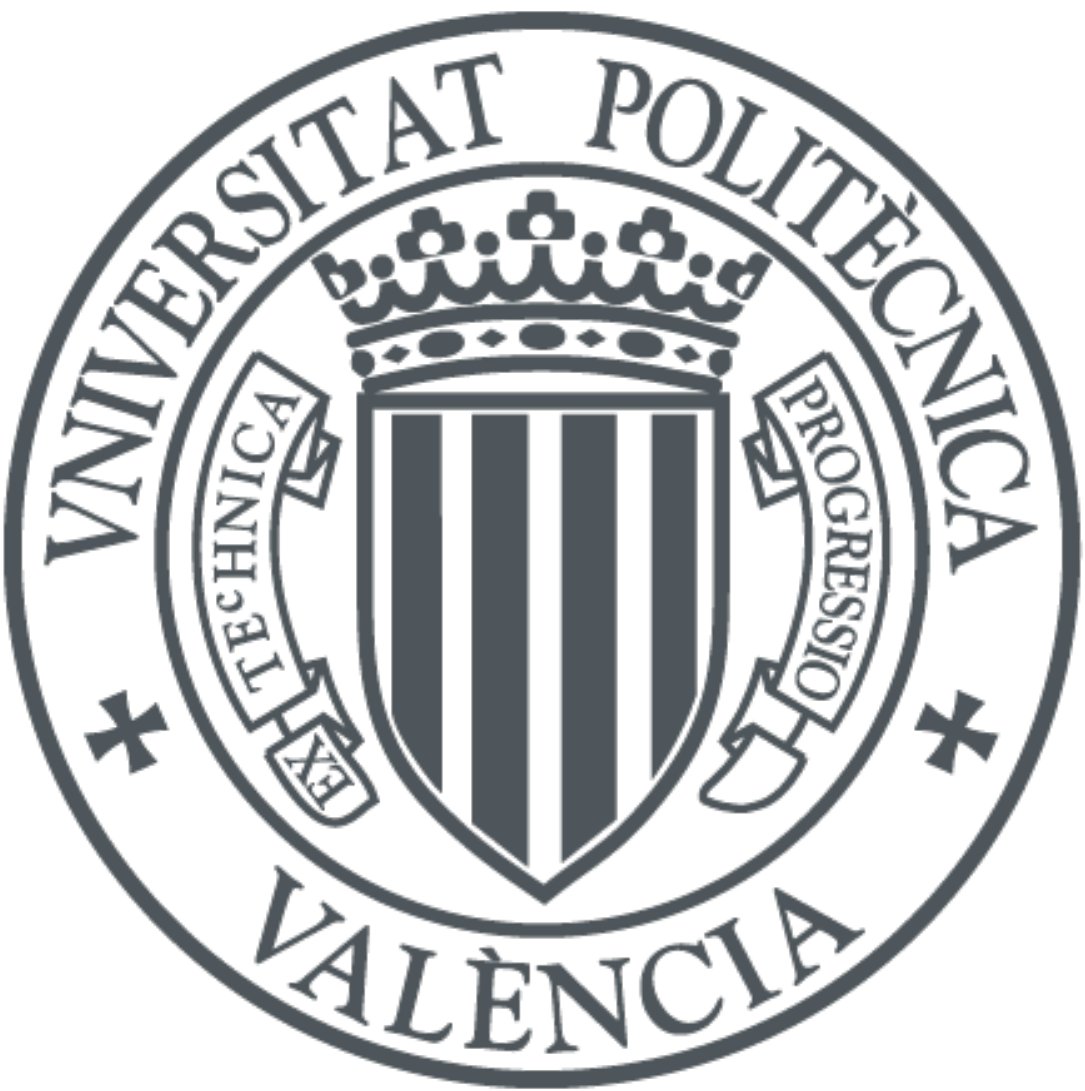

The final publication is available at

http://dx.doi.org/10.1016/j.jas.2011.10.012

Copyright Elsevier

Additional Information 


\title{
ARCHAEOLOGICAL MICROGRAVIMETRIC PROSPECTION INSIDE DON CHURCH (VALENCIA, SPAIN)
}

Jorge Padín, Angel Martín*, Ana Belén Anquela

Department of Cartographic Engineering, Geodesy and Photogrammetry, Polytechnic University of Valencia, C\Camino de Vera s/n, Valencia 46022, Spain.

* Corresponding author. Tel +(34) 96-3877007.

E-mail adress: aemartin@upvnet.upv.es

\begin{abstract}
The microgravimetric surveying technique is applicable to the detection of shallow subsurface structures if a lateral density contrast is presented, and thus, it is a valid technique for archaeological prospection. In this paper, this technique has been revealed to be an efficient tool for archaeological studies, such as those performed inside Don Church (18th century), located in the urban area of Alfafar town, Valencia (Spain), where a buried crypt, suggested by different boreholes drilled during the second restoration process in 1993, is expected. Details of the site's characteristics, topographic survey procedures, microgravimetric field operations, data collection and gravity reduction operations (where the inner building effect of walls, pillars and the altar is confirmed as one of the most important) are also presented. Finally, the results confirm the buried crypt.
\end{abstract}


Keywords: Microgravimetric survey; archaeological prospection; Don Church; Valencia.

\section{Introduction}

Gravity and microgravimetric studies have been widely and routinely used in geophysics, geodesy, geodynamics, geology, mineral and oil exploration and engineering applications (Burger, 1992; Sharma, 1997; Torge, 1989). Likewise, bibliographic references regarding the application of the microgravimetric technique in archaeological prospection are numerous; for example, microgravimetric and gravity gradient techniques are applied in Butler (1984) for the detection of subsurface cavities and tunnels; Friedrich et al. (1996) used microgravimetry to detect hidden cavities and cisterns in the Hagia Sophia's subsurface structure, confirming the accuracy and efficiency of this technique to investigate subsurface structures of historical buildings; Ranieri and Sambuelli (1996) evaluated the use of microgravity measurements to characterise density anomalies in surrounding tunnels; Yule et al. (1998) conducted a microgravimetric investigation to detect subsurface cavities or other anomalous conditions that could threaten the stability of switchyard structures; Beres et al. (2001), Styles et al. (2005) and Leucci and De Giorgi (2010) used microgravimetric surveys to map subsurface karstic features; Ebrahimzadeh (2004) used microgravity measurements to detect subsurface cavities or other anomalous conditions that threaten the stability of the foundation in the technical University of Tehran; Rodríguez et al. (2007) conducted a microgravimetric study in the Vall de Crist Carthusian Monestery (Castellón, Spain) to detect and map a shallow subsurface rainwater cistern, proving that the microgravimetric technique is an efficient tool for cultural heritage restoration studies; 
and finally, the microgravimetric technique has proven useful in urban areas to map well-defined structures, such as doline filled with urban debris (Mochales et al., 2008).

In this paper, we report a microgravimetric prospection study for archaeological purposes inside a historical building. The first part of the paper is devoted to the theoretical methodology and practical considerations to reduce, correct and process the microgravimetric observations. The second part presents the church and the microgravimetric maps related to the reductions, corrections and processing of the observations, which are followed by the final map of the local residual Bouguer anomalies. A microgravimetric inversion of a cross-section and analysis and discussion of the results ends this section. The paper ends with some conclusions about the utility of the technique, including practical considerations for a good microgravimetric survey and the archaeological benefits obtained in the Don Church prospection.

Therefore, this paper can be considered as a case study of microgravimetric technique applied to archaeological prospection. All the reductions and corrections to the gravimetric observations are applied (most of the references before did not include the complete sequence but only some of them), where we highlight the inner building effect as one of the most important in the reduction process when the propection is located inside a building. 


\section{Methodology}

\subsection{Survey details and field procedures}

Data were collected with the Lacoste \& Romberg D203 gravity meter. This gravity meter has electronic levels and is equipped with an electrostatic feedback system. The nominal sensitivity is approximately $1 \mu \mathrm{Gal}\left(1 \mu \mathrm{Gal}=1.10^{-8} \mathrm{~ms}^{-2}\right)$; however, its use in field conditions introduces accidental errors in the observations that should be appropriatelly minimised to achieve relative observations with an accuracy of 5-7 $\mu \mathrm{Gal}$. A list of error sources, their standard deviations and additional precautions to be adopted to minimise their impact can be found in Torge (1989) and Qianshen et al. (1996). These additional precautions include orientation of the instrument with respect to the magnetic field, the readings can only be taken 5 minutes after releasing the clamp, at least three readings should be performed for each station using only the feedback system, and hand carrying was employed during the survey to avoid vibration shock and to ensure careful operation.

In the case study presented, the gravity station grid was marked on the floor with chalk, and the nodes were used for gravity observations. The rules used for the station spacing and field operations with the Lacoste \& Romberg are described in Qianshen et al. (1996).

A total-station surveying instrument was used to determine the horizontal and vertical positions of the station points in a local reference frame with an error better than $0.02 \mathrm{~m}$. Microgravimetric surveys require effective and accurate consideration of the effects 
given by infrastructures, such as buildings (including which the microgravimetric survey is performed), as well as those given by topography near a gravity station. A local survey with the same total-station was performed for the sake of terrain and building corrections.

\subsection{Gravity corrections and reductions}

Corrections to microgravimetric observations are needed to compensate gravity variations due to natural causes (earth tides or atmospheric variations), instrumental causes (drift), observational causes (instrumental height) or geographical situation causes (variations in latitude or corrections for terrain and buildings). In the following, these corrections are presented in the same order as they are applied to the raw microgravimetric data. They are well known since many decades and are applied in a standard way, so a short description is only need.

\subsubsection{Tidal effects and correction}

To predict the tide component, version 3.32 of Professor Wenzel's ETERNA software package with Hartmann-Wenzel Earth tide catalogue was used (Wenzel, 1999).

Parameters for amplitude and phase-difference for the principal tidal waves were fixed to zero and 1.164, respectively (Boedecker, 1988). 


\subsubsection{Instrumental height correction}

For the purpose of reducing the gravimetric reading to the ground mark, the theoretical free-air gradient of $308.6 \mu \mathrm{Gal}$ by one meter was used, and the height of the instrument above the station level was carefully measured (Torge, 1989).

\subsubsection{Atmospheric pressure correction}

This reduction has to be applied to account for the difference between the actual atmospheric pressure and the normal atmospheric pressure at the station (Boedecker and Ritcher, 1981). International Association of Geodesy (IAG) resolution No 9, recommends the use of the following formulae for atmospheric gravity reduction (Torge, 1989):

$$
\begin{gathered}
d g_{P}=0.30\left(P_{i}-P_{i n}\right) \quad \mu G a l \\
P_{i n}=1013.25\left(1-\frac{0.0065 H}{288.15}\right)^{5.2559}
\end{gathered}
$$

where $H$ is the orthometric height of the station, $P_{i}$ is the measured value of the pressure at the station and $P_{\text {in }}$ is the normal pressure (both in $\mathrm{hPa}$ ). 


\subsubsection{Instrumental drift and drift correction}

The drift of the Lacoste \& Romberg D203 gravity meter can be considered linear for short periods of time (6-8 hours), (Martín et al., 2011) and it is corrected applying this linear behaviour to the rest of the readings based on repeated measurements at base stations.

\subsubsection{Latitude correction (normal gravity correction)}

The rotation of the Earth and its nonspherical shape produce an increase in gravity values with latitude that can be taken into account by subtracting the normal ellipsoidal gravity to the observations, or, for the relatively small areas of microgravity surveys, it is sufficient to assign a reference latitude to the base station and to use the following expression to take into account the augmentation of gravity on the North direction (Qianshen et al., 1996):

$d g_{P}= \pm 0.81 \sin 2 \psi \Delta L \quad \mu G a l$

where $\Delta L$ is the distance to the North or South direction to the base station in meters, and $\psi$ is the reference latitude (latitude of the base station). This correction is positive if the station is located south of the base station; otherwise, it is negative. 


\subsubsection{Free-air and Bouguer correcion}

The free-air and Bouguer corrections are computed through the following equation (Ebrahimzadeh, 2004; Torge, 1989; Yule et al., 1997):

$d g_{F+B}= \pm(308.6-41.91 \rho) \Delta h \quad \mu G a l$

where $\rho$ is the average density of the materials and $\Delta \mathrm{h}$ is the difference in metres between the elevation of the measurement station and the elevation of the reference level. The sign of this equation is positive if the reference level is under the measurement level and negative if it is higher.

\subsubsection{Terrain correction}

Bouguer correction is completed with the terrain correction (Torge, 1989). The expression of Nagy (Nagy, 1966), based on the attraction generated by a rectangular prism, is used to compute this correction:

$$
d g_{t}=G \rho \|-x \ln (y+r)-y \ln (x+r)+\left.\left.\left.z \arctan \left(\frac{x y}{z r}\right)\right|_{x_{1}} ^{x_{2}}\right|_{y_{1}} ^{y_{2}}\right|_{z_{1}} ^{z_{2}}
$$

where $G$ is the gravitational constant, $\rho$ is the mean density of the topography and $r=\sqrt{x^{2}+y^{2}+z^{2}}$, where the coordinate system is a local one centred on the observation point, so that it changes for every microgravimetric station. 


\subsubsection{Correction for building effects}

In microgravimetry, particular caution should be taken in correcting for buildings, as their effect can be greater than the amplitude of the expected anomalies (Debeglia and Dupont, 2002, Qianshen et al., 1996). Most buildings have a regular geometrical shape or various compositions of certain regular geometric elements (e.g., cylinder, sphere, rectangle), and thus, the computation of the attraction they exert can be performed using equation 4 . The precision of this correction depends on the accuracy of the digital model of the elements of these buildings and on the correct adoption of the mean density value for walls, pillars, floors or roofs. An alternative procedure to computing an estimation of the mean density for the building corrections and mean values for that densities can be found in Qianshen et al. (1996), page 63.

In our case, the most important building to take into account is the one for which the survey is being conducted (it can be named the inner building). One important aspect to take into account is that the inner building effect could be extremely high for points situated very near the element ( 2 metres or less), where the gradient introduced by the element (a wall for example) is difficult to estimate and can introduce a significant distorsion effect in the gravity observation. This effect can be seen in Fig. 1, where the influence of a rectangular building with 1 metre wide walls with a $2.1 \mathrm{gr} / \mathrm{cm}^{3}$ density and a height of 10 metres is modelled, suggesting that observations near the walls should not be done.

FIGURE 1 


\title{
2.3 Data processing
} \\ When all the corrections and reductions explained in section 2.2 have been applied to \\ the microgravimetric observations, the final Bouguer gravities are obtained, $g_{B}$. \\ Subtracting the Bouguer gravity obtained at the base station, $g_{\text {base }}$, from the Bouguer \\ gravities at each station by \\ $\Delta g_{B}=g_{B}-g_{\text {base }}$
}

results in the final residual Bouguer gravity anomaly. In the same way, the term "residual" can be applied to the gravity observations (that is 'residual gravity observations') if they are formed by subtracting the gravity observation at the base station to the gravity observations at each station.

\begin{abstract}
After the computation of the final residual Bouguer gravity anomalies, separation between local and regional gravimetric components is needed to differentiate between anomalies from local, near surface masses (which are of interest in this kind of studies) and those arising from larger and deeper structures (Dobrin and Savit, 1988; Torge, 1989; Sharma, 1997). Due to the small dimensions of the studied areas in archaeological research, the adjustment of a low degree polynomial to the final residual Bouguer gravity anomaly is recommended, so it is assumed that a polynomial surface adequately models the field's regional component (see for instance, Camacho et al., 1994; Montesinos et al., 1999).
\end{abstract}


If the microgravity observation is performed in the nodes of a grid, the contour maps can be created directly without any interpolation technique consideration or error, but if the nodes do not conform to a regular grid an interpolation is needed. A geostatistical method such as kriging is highly recommended.

Finally, these contour maps are the basis of the analysis, discussion and conclusions.

\section{A Case study: Don Church (Alfafar, Valencia)}

Don Church is located in the urban area of Alfafar town, Valencia (eastern part of Spain). The geological characteristics inside this town are quite homogeneous and can be described as the result of a terrain hollow depression formed in the Miocene era, which was subsequently filled by alluvial deposits. This process generates horizontal layers of marls and clay alternating with gravels and sands.

The actual church was constructed between 1736 and 1748. The church was restored in 1918 and 1993. During the second restoration, the existence of a gothic floor under the present floor was suggested, indicating that the actual church was constructed above another one, so various boreholes were drilled, Fig 2. One of these boreholes (B3 in Fig.

2) showed part of an old wall identified as gothic style. Another one (B1 in Fig. 2) found parts of the ceiling of a buried crypt situated at, approximately, $1 \mathrm{~m}$ under the actual floor. This crypt, apparently, longitudinally crossed the church. Thus, the main objective of the microgravimetric prospection is this crypt. 
The situation of the profiles and the ground plan of the church can be seen in Fig. 2. The 8 profiles are situated at least 2 metres away from the walls. The observed points in these profiles are separated by 1 metre in the central area, where the crypt was expected, and 2 metres out of this area. Finally Fifty-one points have been observed (including the base station). A precise topographic survey of the terrain (Fig. 3), the nearby buildings (Fig. 4), and the structures of the church (black elements in Fig. 2), was performed.

Fig. 5 shows the plot of the observed residual gravity anomalies correcting the observations only for tide, instrumental height, atmospheric and drift effects, where the situation of the altar ( 0.6 metre above the floor) is clearly drawn. The statistical resume of these values can also be found in table 1 .

A density value of $2.1 \mathrm{gr} / \mathrm{cm}^{3}$ is introduced for Bouguer and terrain correction. This value is the mean density for marls, clay, gravels and sands (Telford et al., 1990), that is the mean density of the geological materials located in the survey area.

\footnotetext{
After latitude, free-air, Bouguer, terrain and near-buildings corrections (Fig. 6), the situation of the altar is blurred, and the geometry of the prospection presents higher gravity anomaly values in the centre of the church than in the periferic areas. This geometry is caused by the construction elements of the church (walls and pillars). Fig. 7 presents the correction of these near elements, showing the typical cross-configuration of a church (it can be compared with Fig. 2). The gravimetric effect of the structure of the altar is separeted, Fig. 8 , because the density of this structure is low to that considered in the Bouguer correction (the altar is constructed by the introduction of compacted debris material over the original terrain, not over the original terrain
} 
directly), so an excess in density is introduced in the Bouguer correction and should be eliminated. Finally, Fig. 9 presents the final residual Bouguer anomalies corrected by the effect of all these near elements. In table 1 the statistical resume of residual Bouguer anomalies and residual Bouguer anomalies after correction for these structural features can be found. The standard deviation is reduced from 58 to $13-15 \mu \mathrm{Gal}$ compared with the residual gravity anomalies corrected only for tide, instrumental height, atmospheric and drift effects and the range of the values have been reduced from 186 to 55-60 $\mu \mathrm{Gal}$. These results confirm that the reduction process eliminates the major part of the gravimetric signal and only the interested part, located in the floor of the church, is retained.

Given the dimensions of the working area and taking into consideration the low gradient of the final residual Bouguer anomalies (Fig. 9), it seems logical to use a one-degree polynomial (that is, a plane) for local-regional gravimetric field separation. The adjusted polynomial surface can be seen in Fig. 10, and the result obtained after the substraction of this polynomial surface to the final residual Bouguer anomalies, that is, the final local residual Bouguer anomalies, can be seen in Fig. 11. The last column of table 1 give the statistical resume. The statistical behaviour is similar to the column corresponding to the final residual Bouguer anomalies.

In figure 11, the footprint of the expected longitudinal crypt, corresponding to a low longitudinal gravity anomaly values can be seen. Low longitudinal gravity anomaly value can be seen in the entrance of the church, the same low gravity anomaly is located in the altar but without the longitudinal trend. The low gravity anomalies disappears in the centre of the church, most likely due to a full up process with debris material in this 
part of the crypt in the construction process of the actual church, or simply because the crypt did not cross all the church in a longitudinal way: it ends 6-7 meters away the entrance and the low gravity anomalies localted in the altar could be still influenced by the presence of the altar.

\section{FIGURE 2}

FIGURE 3

FIGURE 4

FIGURE 5

FIGURE 6

FIGURE 7

FIGURE 8

FIGURE 9

FIGURE 10

FIGURE 11

A microgravimetric inversion was performed in the AA' cross-section (Fig. 11) to fit the expected crypt to the final local residual Bouguer anomalies. The modelling was carried out with the GravModeler software, which performs 2D modelling of gravity data based on the line integral approach of the classical Talwani method (Talwani et al., 1959) using bodies of various densities embedded within a homogeneous background.

An empty (cero density value) rectangle $2.5 \mathrm{~m}$ wide and $1.2 \mathrm{~m}$ high, located $1 \mathrm{~m}$ under the actual floor can explain the microgravimetric differences observed in the crosssection (Fig. 12). Finally, this rectangle can be linked to the expected crypt. 
FIGURE 10

\section{Conclusions}

The microgravimetric survey proved to be a valid technique for archaeological prospection due to its capacity to detect and delineate shallow structures (including surrounding ones). To obtain a clear interpretation of the Bouguer anomalies, all reductions and corrections should be applied carefully and with maximum rigour to the raw microgravimetric observations. Special emphasis should be placed on structural near elements, where the gravimetric observation must be made at a distance greater that 2 metres from the elements to avoid possible distortions in the gravimetric signal. A case study is performed in Don Church, where the expected crypt seems to be clearly found in the entrance of the church, confirming the previous suggestions based on the boreholes.

\section{Acknowledgements}

The authors would like to thank Susana De La Rubia and Blas Guijarro the opportunity to develop this prospection. The two anonymous reviewers are kindly acknowledge for their contribution with valuable comments and suggestions. 


\section{References}

Beres, M., Luetscher, M., Olivier, R., 2001. Integration of ground-penetrating radar and microgravimetric methods to map shallow caves. J. Appl. Geophys. 46, 249-262.

Boedecker, G., 1988. Absolute gravity observations, data processing standards and station documentation. Bull. Inf. Bur. Gravim. Int. 63, 51-57.

Boedecker, G., Ritcher, B., 1981. The new gravity base net 1976 of the Federal Republic of Germany (DSGN 76). Bull. Geod. 55, 250-266.

Burger, H.R., 1992. Explorations geophysics of the shallow subsurface. Prentice Hall, Englewood Cliffs, London.

Butler, D.K., 1984. Microgravimetric and gravity gradient techniques for detection of subsurface cavities. Geophys. 49(7), 1084-1096.

Camacho, A. G., Montesinos, F.G., Vieira, R., 1997. A three-dimentional gravity inversion applied to Sao Miguel Island (Azores). J. Geophys. Res., 102(B4), 7717-7730.

Debeglia, N., Dupont, F., 2002. Some critical factors for engineering and environmental microgravity investigations. J. Appl. Geophys. 50, 435-454.

Dobrin, M.B., Savit, C H., 1988. Introduction to geophysical prospecting. Fourth edition. McGraw-Hill, Inc. 
Ebrahimzadeh, V., 2004. Microgravity investigations of foundation conditions. J. Earth \& Space Phys. 30(1), 11-14.

Friedrich, J., Gerstenecker, C., Gürkan, O., 1996. Gravimetric examination of Hagia Sophia’s subsurface structure. J. Geod. 70, 645-651.

Leucci, G., De Giorgi L., 2010. Microgravimetric and ground penetrating radar geophysical methods to map the shallow karstic cavities network in a coastal area (Marina Di Capilungo, Lecce, Italy). Exploration Geophys. 41, 178-188.

Martín, A., Anquela, A.B., Padín, J., Berné, J.L., 2011. On standard reductions to relative gravity measurements. a case study through the establishment of the new local gravity net in the province of Valencia (Spain). Surv. Rev. 43(319), 16-29.

Mochales, T., Casas, A.M., Pueyo, E.L., Pueyo, O., Román, M.T., Pocoví, A., Soriano, M.A., Ansón, D., 2008. Detection of underground cavities by combining gravity, magnetic and ground penetrating radar surveys: a case study from the Zaragoza area, NE Spain. Environ. Geol. 53, 1067-1077.

Montesinos, F.G., Camacho, A.G., Vieira, R., 1999. Análisis of gravimetric anomalies in Furnas Caldera (Sao Miguel, Azores), J. Volcanol. and Geotherm. Res., 92(1-2), 6781 
Nagy, D., 1966. The gravitational attraction of a right angular prism. Geophys. 31, 362371.

Qianshen, W., Chijun, Z., Fuzhen, J., Wenhu Z., 1996. Microgravimetry. Science Press, Beijing, China.

Ranieri, G., Sambuelli, L., 1996. A new procedure to perform differential underground gravity measurements. J. Appl. Geophys. 36, 123-129.

Rodríguez, I., García, F., Rodríguez, Ir. Ramírez, M., Montalvo, J.L., Benlloch, J., Capuz, R., 2007. Non-destructive assessment of a buried rainwarer cisterna at the Carthusian Monastery "Vall de Crist" (Spain, 14th century) derived by microgravimetric 2D modelling. J. cultural herit. 8, 197-201.

Sharma, P.V., 1997. Environmental and engineering geophysics. Cambridge University Press.

Styles, P., McGrath, R., Thomas, E., Cassidy, N.J., 2005. The use of microgravimetry for cavity characterization in karstic terrains. Q. J. Engineer. Geolog. and hydrogeolog. $38,155-169$.

Talwani, M., Worzel, J.L., Landisman, M., 1959. Rapid gravity computations for twodimensional bodies with application to the Mendocino submarine fracture zone. J. Geophys. Res. 64(1), 49-61. 
Telford, W.M., Geldart, L.P., Sheriff, R.E., 1990. Applied Geophysics. $2^{\text {nd }}$ edition. Cambridge University Press.

Torge, W., 1989. Gravimetry. Ed. Walter de Gruyter.

Wenzel, G., 1999. Earth tide data processing package, Eterna version 3.32. User manual.

Yule, D.E., Sharp, M.K., Butler, D.K., 1998. Microgravity investigations of foundation conditions. Geophys. 63(1), 95-106. 


\section{FIGURE CAPTIONS}

Fig. 1. Example of the influence of rectangular building on microgravimetric observations; for explanations see the text.

Fig. 2. Ground plan of Don Church including the profiles (P1 to P8) used for the microgravimetric observations. Black points represent the location of a borehole.

Fig. 3. Plot of the digital elevation model.

Fig. 4. Map of the near buildings modelled and corrected at the microgravimetric observations.

Fig. 5. Residual gravity anomalies (corrections for tides, instrument height, atmospheric and drift effects).

Fig. 6. Residual Bouguer anomalies (corrections for tides, instrument height, atmospheric effects, drift, latitude, free-air, Bouguer, terrain and near buildings effects).

Fig. 7. Microgravimetric correction for the near elements (walls and pillars).

Fig. 8. Microgravimetric correction for the altar.

Fig. 9. Final residual Bouguer anomalies.

Fig. 10. Adjusted polynomial surface for local-regional gravimetric field separation.

Fig. 11. Final local residual Bouguer anomalies.

Fig. 12. Microgravimetric modelled inversion of AA' cross-section. 
Table 1. Statistical resume for different residual gravity signals. Values are presented un $\mu \mathrm{Gal}$.

\begin{tabular}{|c|c|c|c|c|}
\hline & $\begin{array}{c}\text { Residual } \\
\text { gravity } \\
\text { observations }\end{array}$ & $\begin{array}{c}\text { Residual } \\
\text { Bouguer } \\
\text { anomalies }\end{array}$ & $\begin{array}{c}\text { Residual Bouguer } \\
\text { anomalies after } \\
\text { structures correction }\end{array}$ & $\begin{array}{c}\text { Final local Residual } \\
\text { Bouguer anomalies }\end{array}$ \\
\hline Mean & 37.301 & 58.766 & 41.071 & 40.731 \\
\hline$\sigma$ & 58.757 & 15.717 & 13.362 & 12.626 \\
\hline Max. & 82.856 & 84.488 & 61.159 & 62.148 \\
\hline Min. & -103.549 & 21.872 & 6.197 & 8.464 \\
\hline
\end{tabular}




\section{Figure 1}

Click here to download high resolution image

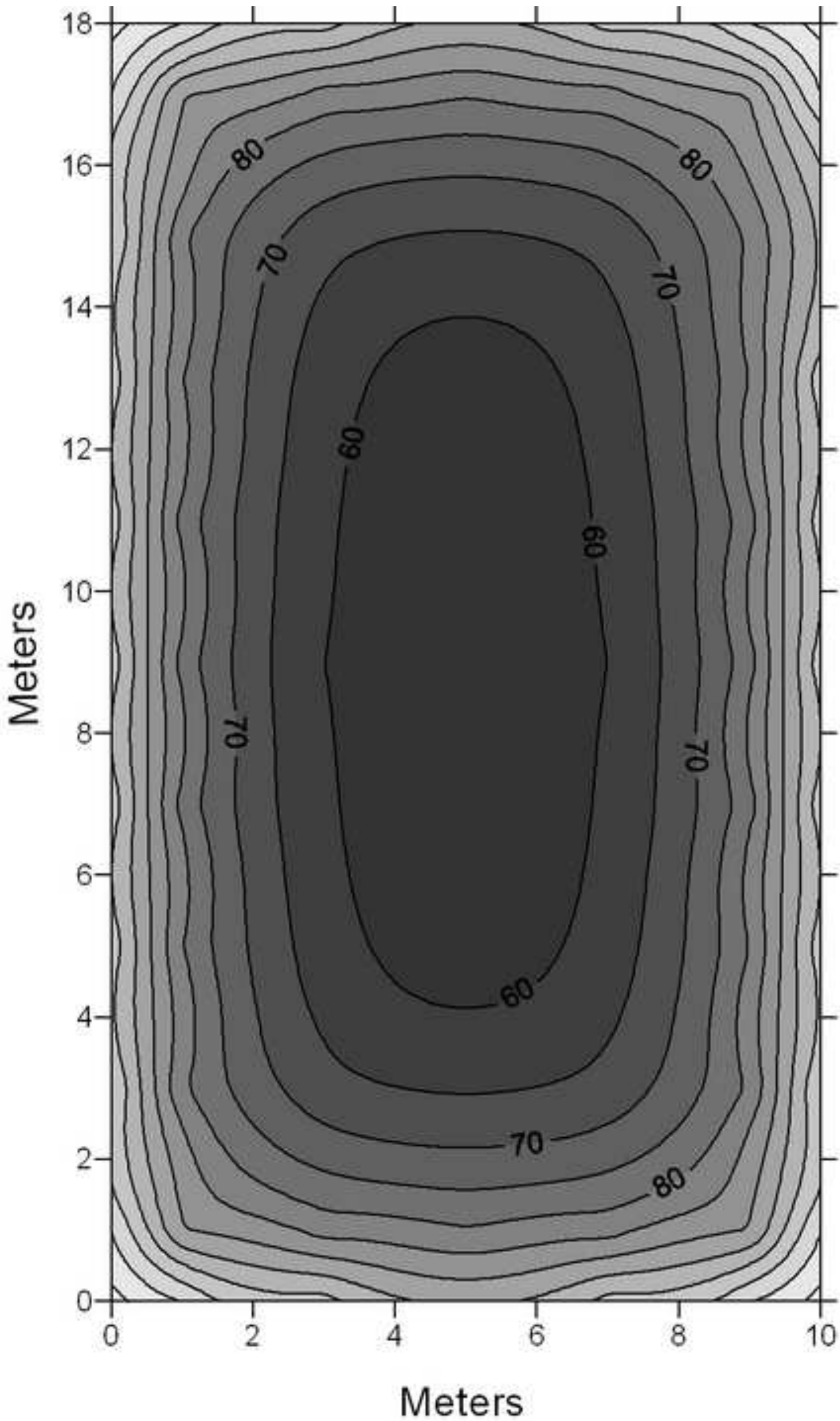

$\mu \mathrm{Gal}$

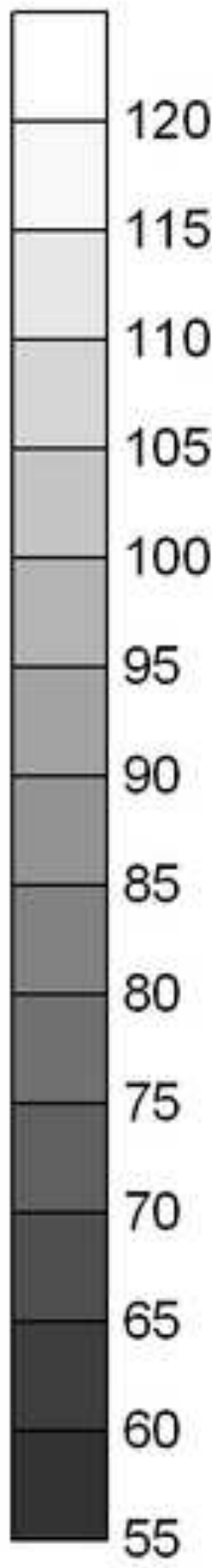

55 


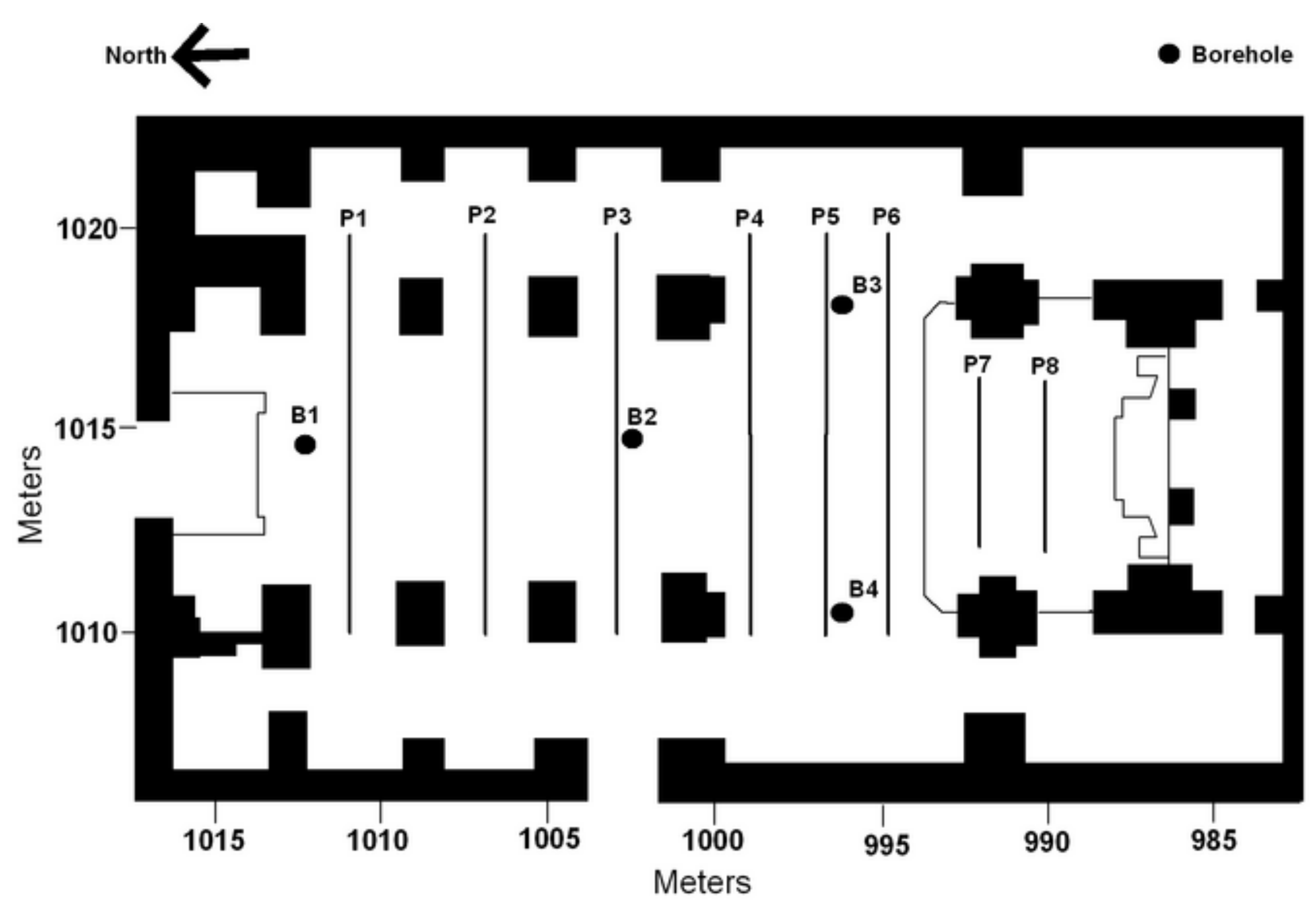

Click here to download high resolution image 


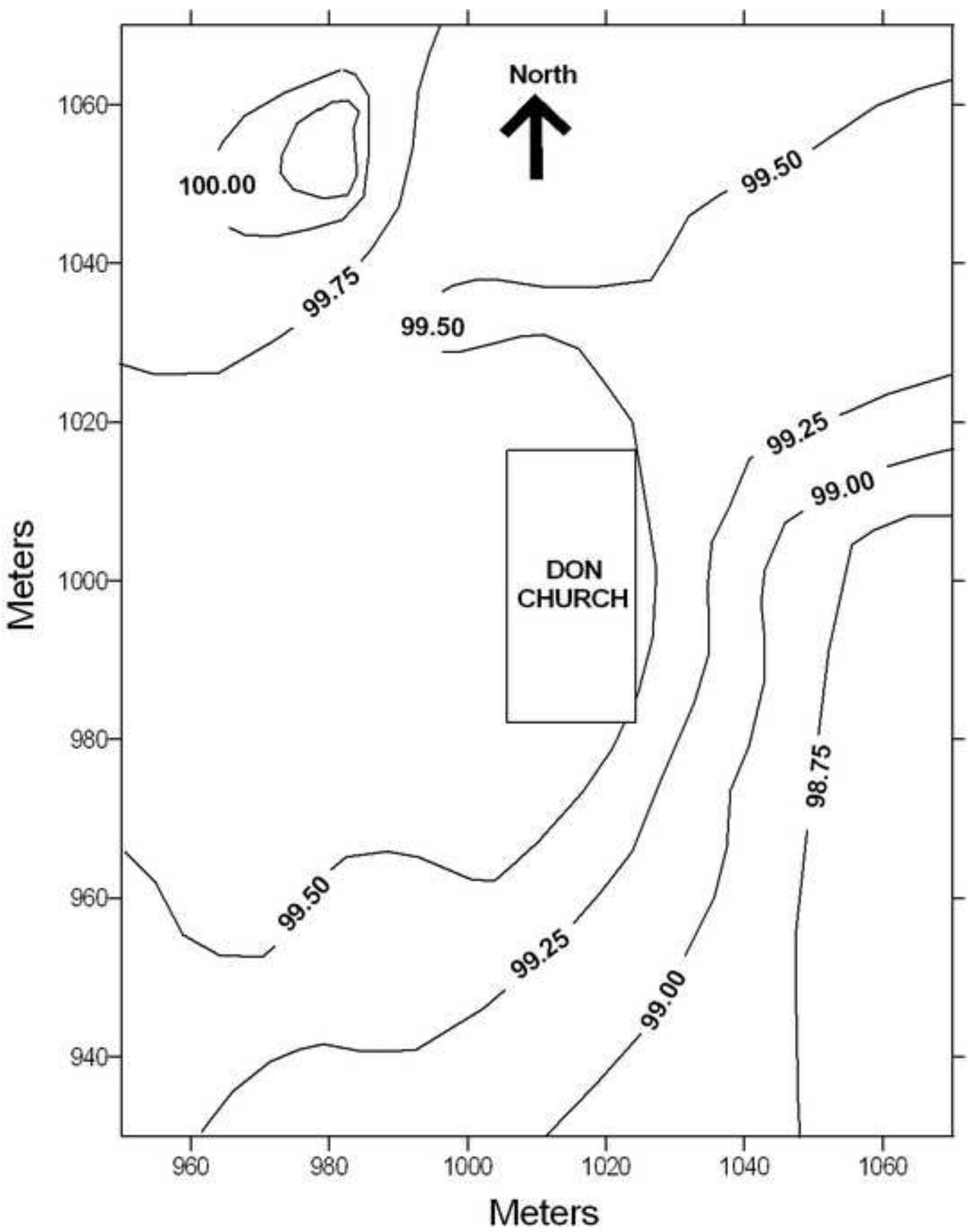




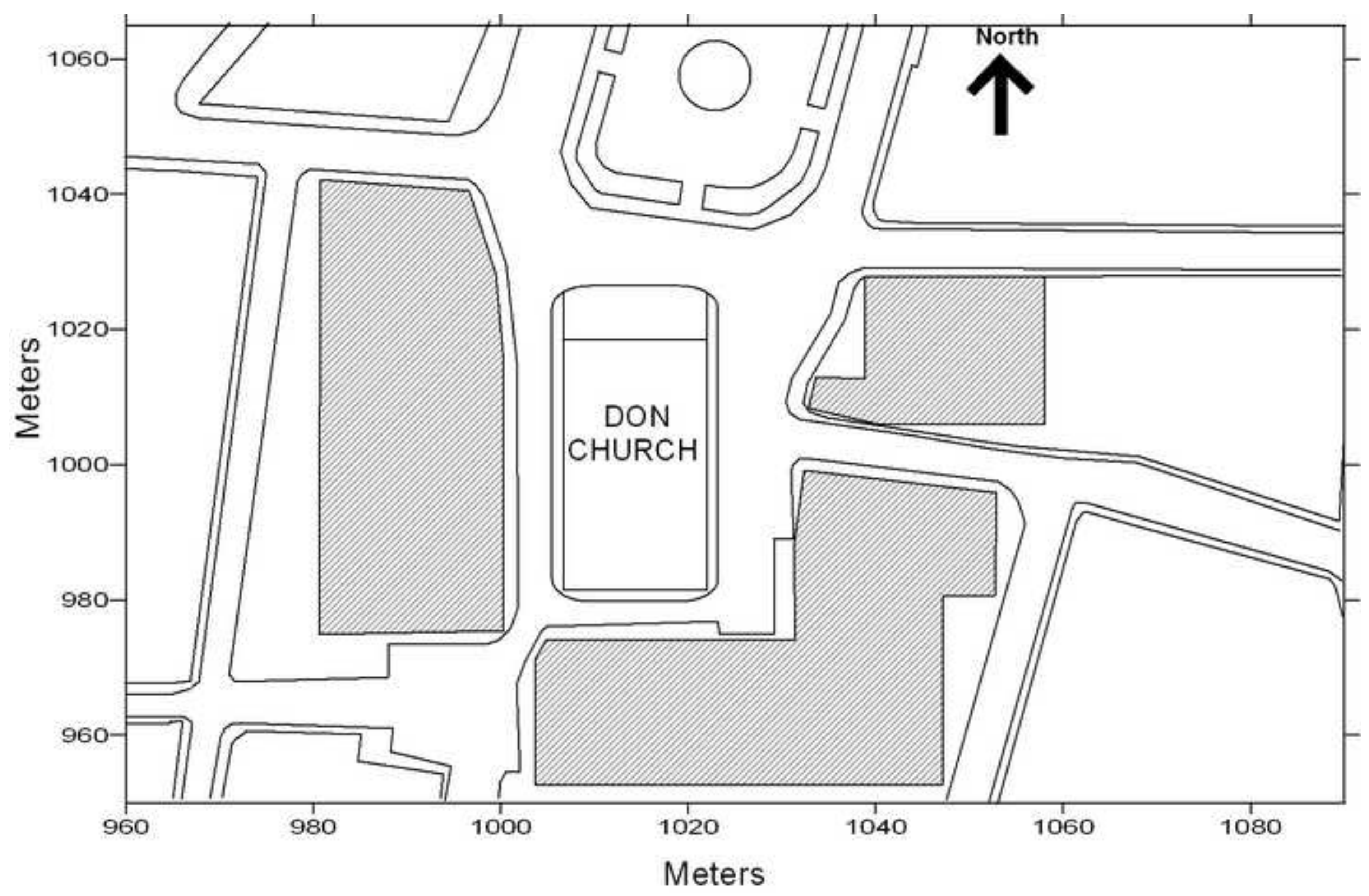




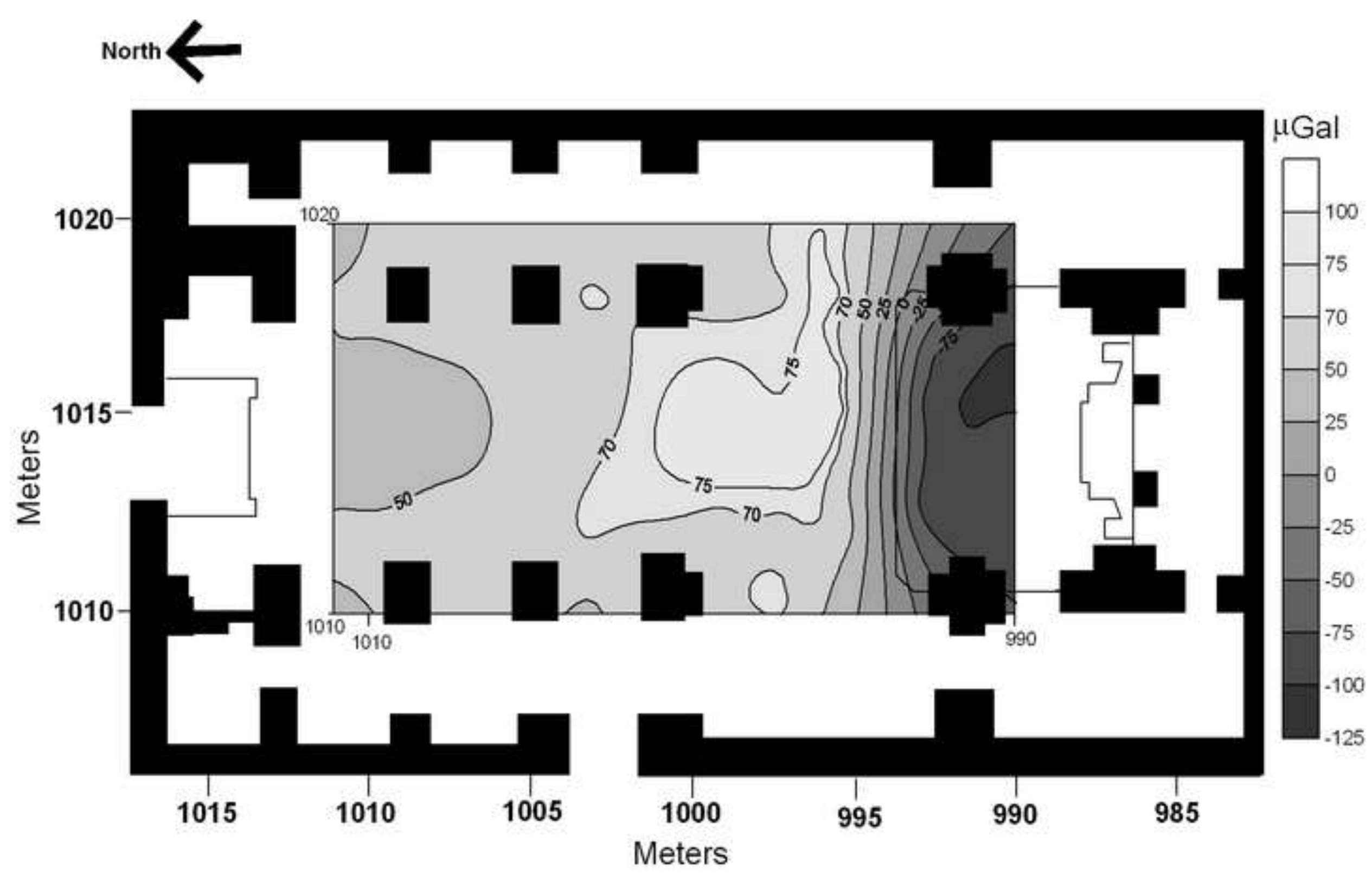

Click here to download high resolution image 


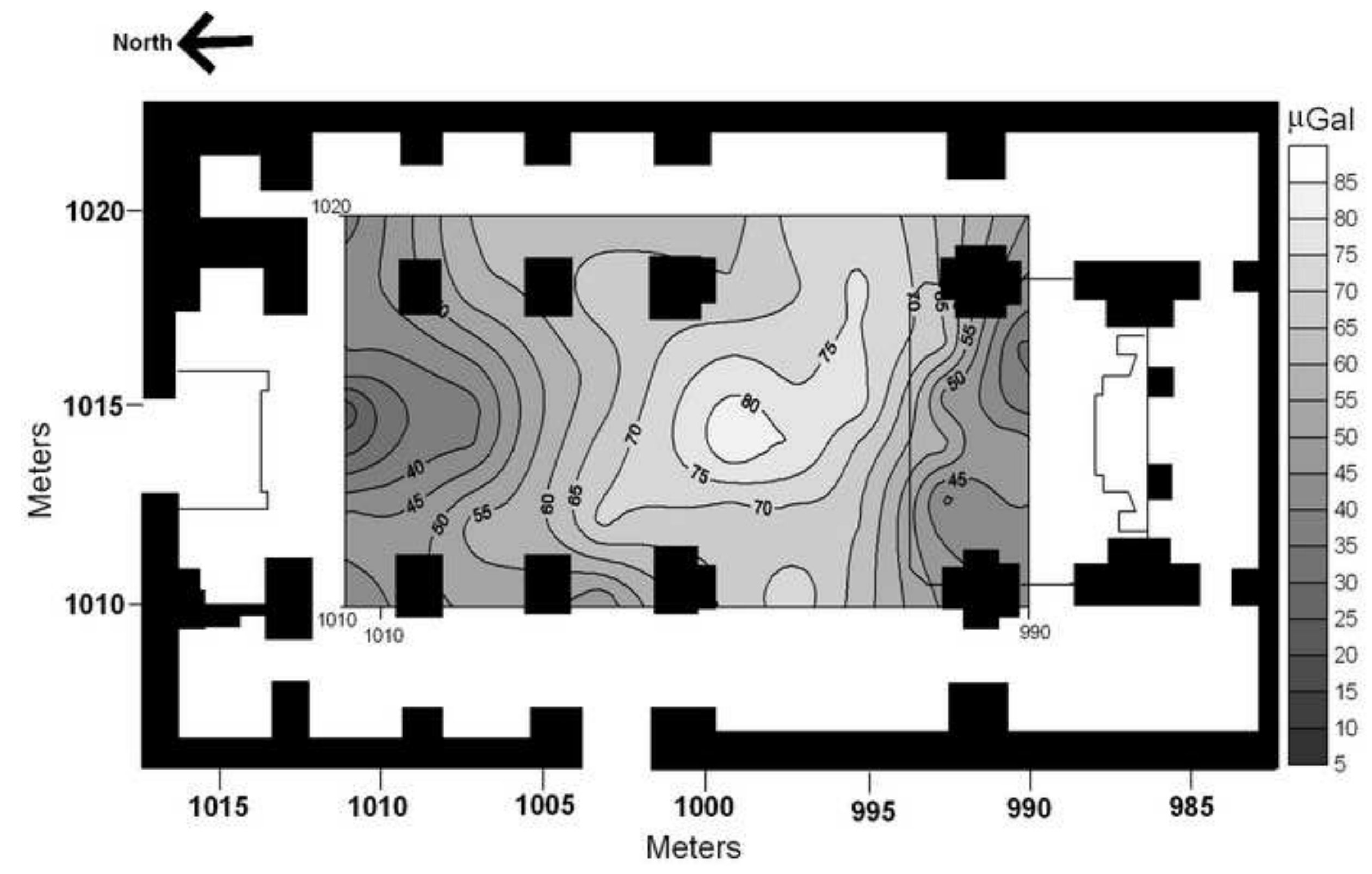




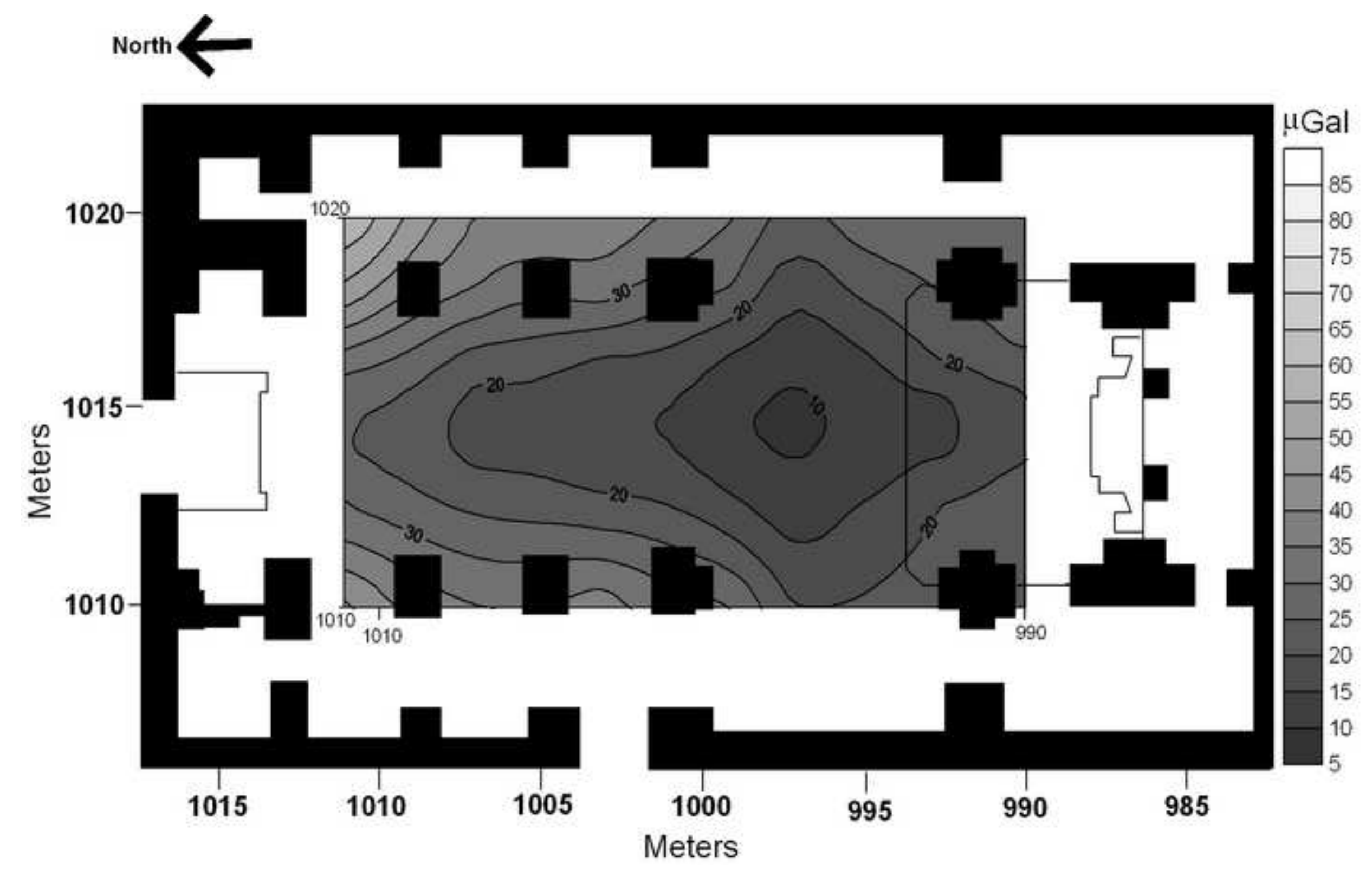

5
(1)

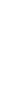




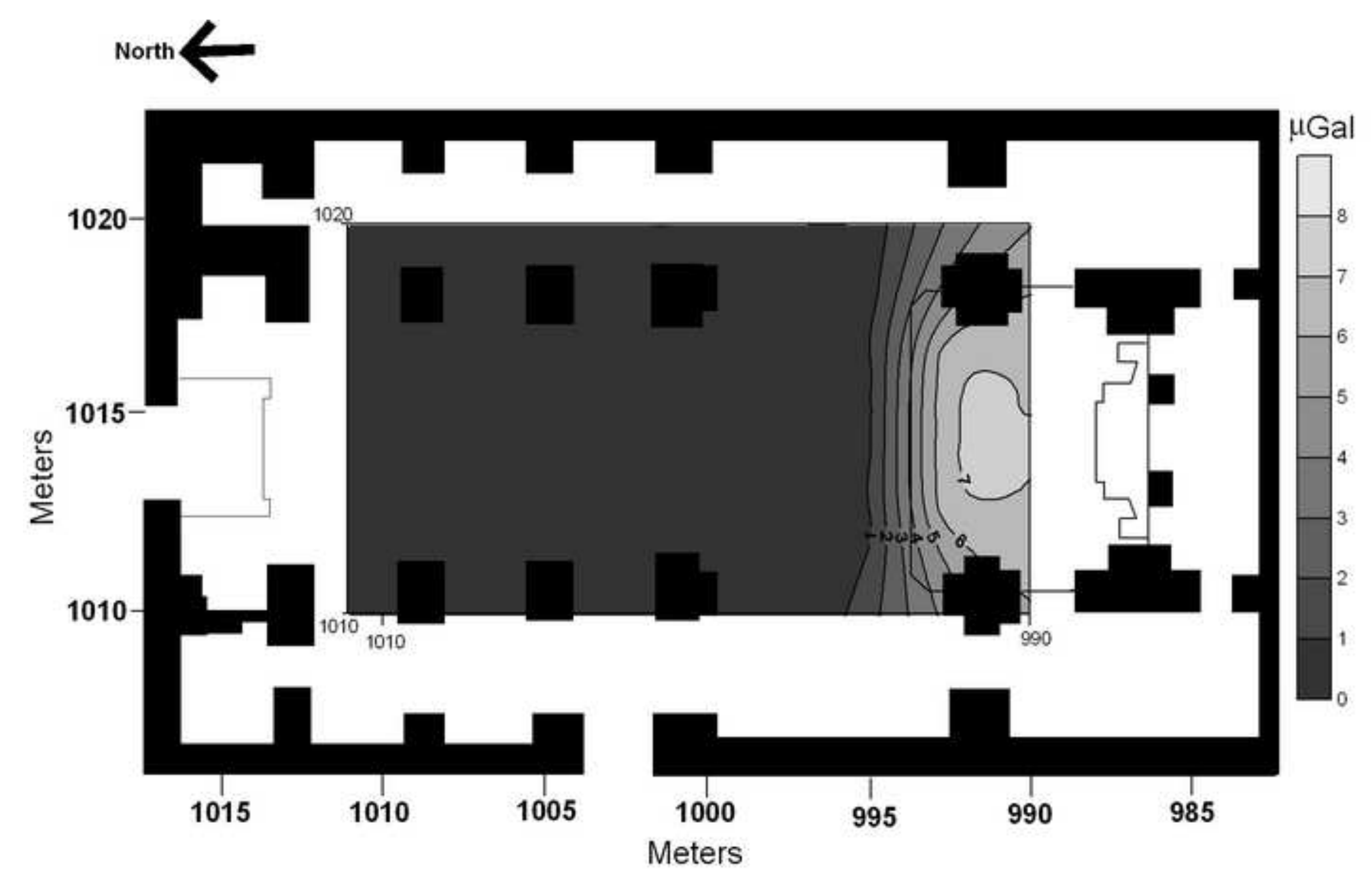

Figure 8
Click here to download high resolution image (

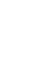
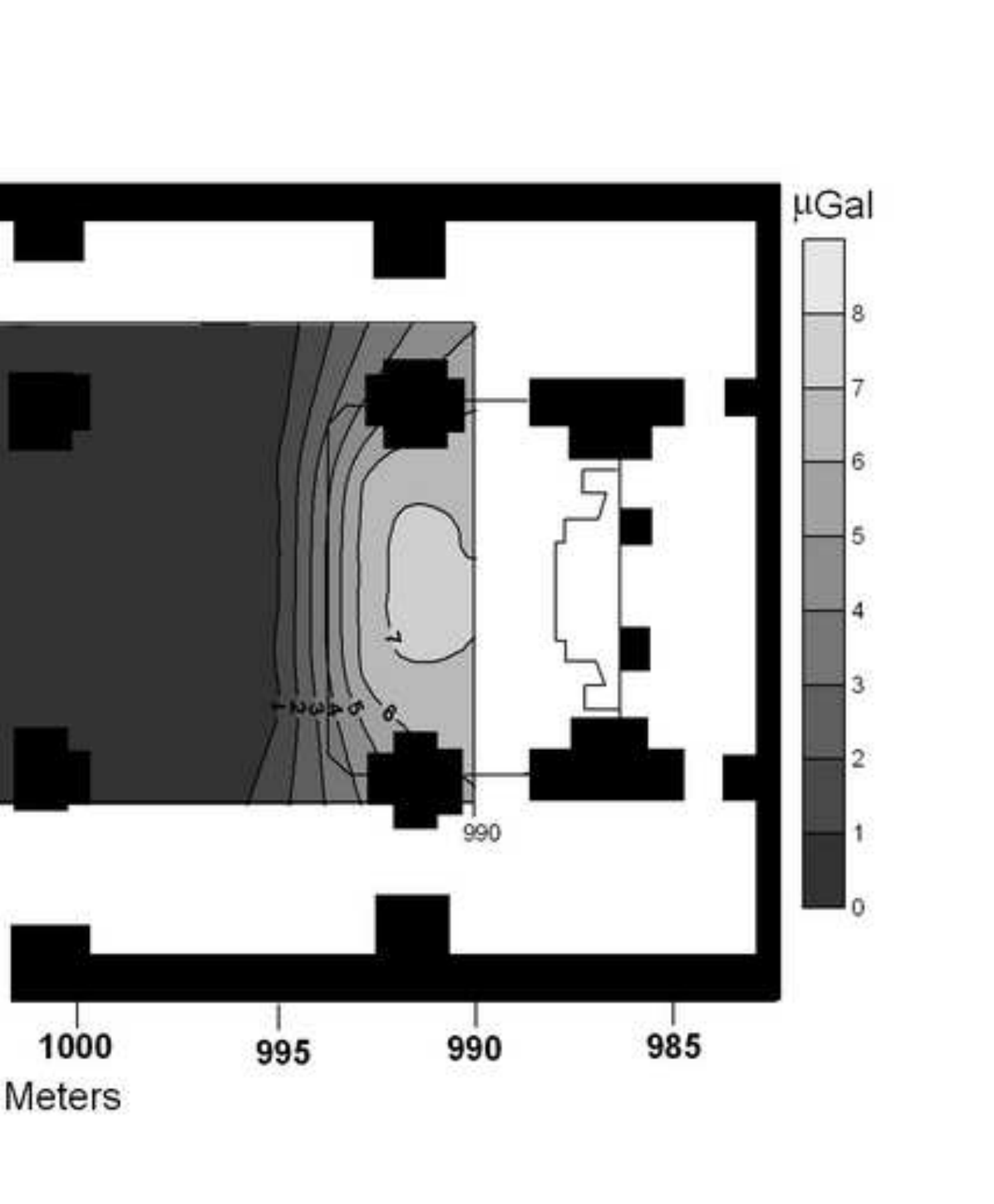


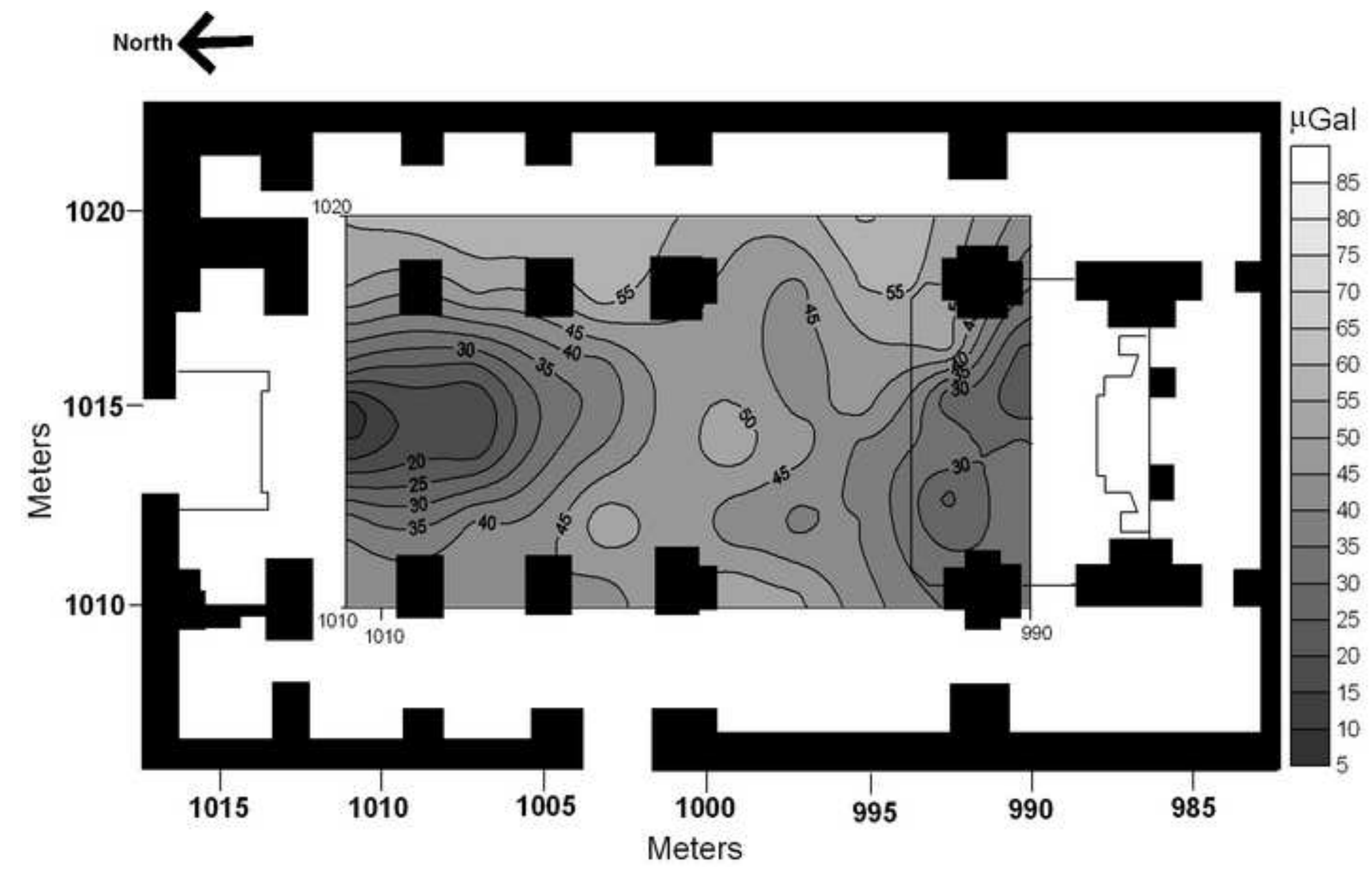


Click here to download high resolution image
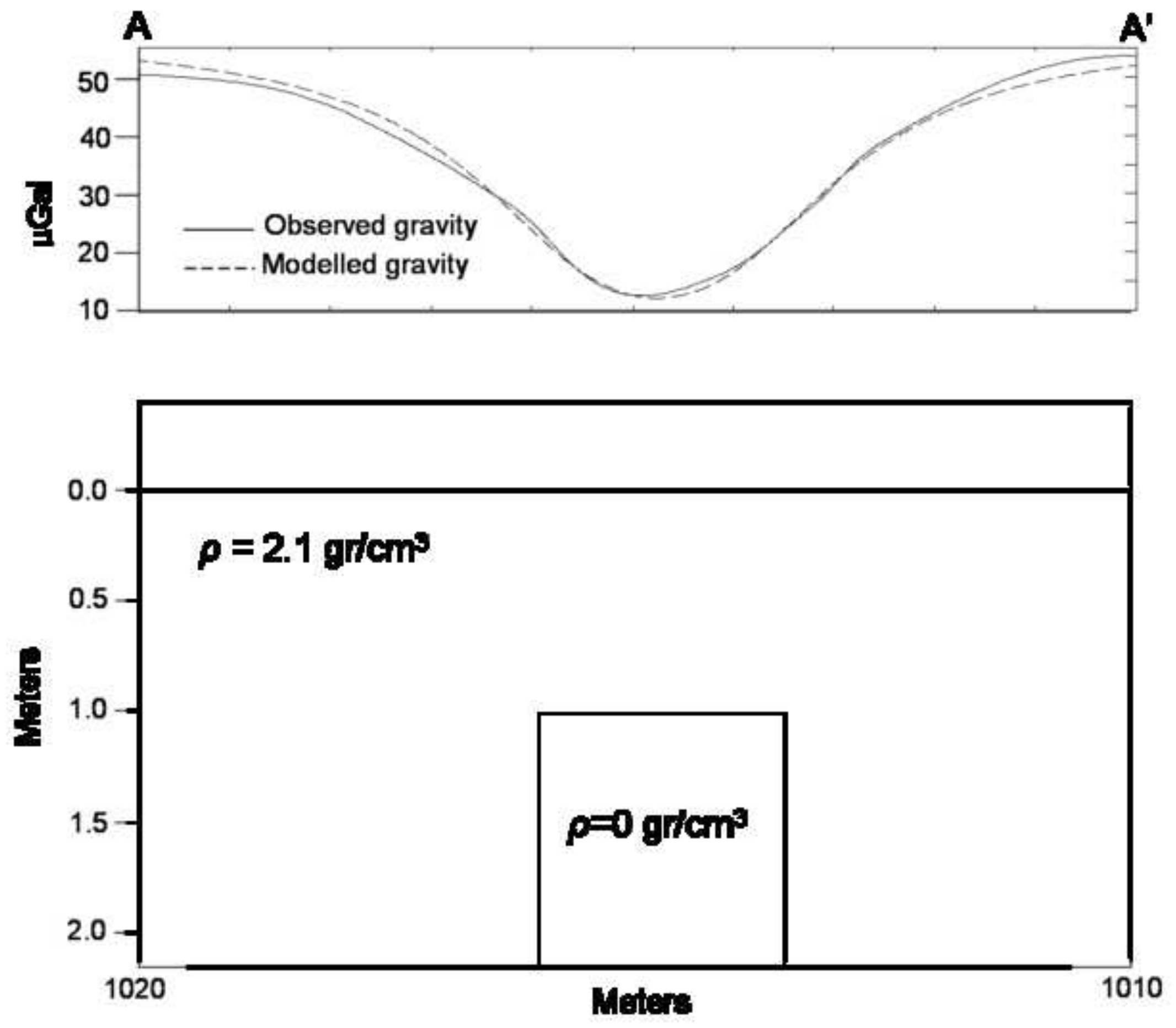